\title{
Coupled coincidence and coupled common fixed point theorems on a metric space with a graph
}

\author{
Dakjum Eshi, Pramod K Das and Pradip Debnath*
}

\section{"Correspondence:}

debnath.pradip@yahoo.com

Department of Mathematics, North

Eastern Regional Institute of Science

and Technology, Nirjuli, Arunachal

Pradesh 791109, India

\section{Springer}

\begin{abstract}
In this paper, our aim is to introduce the concept of G-g-contraction mapping and prove some coupled coincidence and coupled common fixed point theorems for nonlinear contraction mappings in the new set up of partially ordered complete metric spaces endowed with a directed graph. As an application, we apply our results to present an existence theorem for solution of some particular integral equations. Our paper is inspired by the work of Chifu and Petrusel (Fixed Point Theory Appl. 2014:151, 2014); the authors introduced the concept of a coupled fixed point. In the current paper, however, we have established the results by introducing the new notion of a coupled coincidence fixed point instead of the coupled fixed point in the setting of a partially ordered complete metric space with graph.
\end{abstract}

MSC: 55M20; 54H25; 47H09

Keywords: coupled fixed point; coupled coincidence point; coupled common fixed point; metric space with a graph

\section{Introduction with preliminaries}

The advent of the most celebrated fixed point result, the Banach contraction principle, initiated a new era of research in fixed point theory due to its immense applicability in major areas of mathematics like numerical analysis and differential/integral equations. The Banach contraction principle was used to study the fixed points of nonlinear contraction maps by Boyd and Wong [2].

Recently, fixed point results in partially ordered sets have drawn the attention of mathematicians around the world because of its ease of compatibility in modeling various problems. The first attempt in this direction was done by Ran and Reurings [3], which was a combination of the Banach contraction principle and the Knaster-Tarski fixed point theorem. They considered a class of mappings $f: X \rightarrow X$, with $(X, d)$ being a complete metric space and a partial order $\leq$. The mappings they considered are continuous, monotone with respect to the partial order $\leq$. Those mappings also satisfy a Banach contraction inequality for every pair $(x, y) \in X \times X$ such that $x \leq y$. When, for some $x_{0} \in X$, the inequality $x_{0} \leq f\left(x_{0}\right)$ is satisfied, they proved that the Picard sequence $\left\{f^{n}\left(x_{0}\right)\right\}$ would converge to a fixed point of $f$. Ran and Reurings also combined this interesting result with the Schauder fixed point theorem and applied it to obtain some existence and uniqueness results to nonlinear matrix equations.

(c) 2016 Eshi et al. This article is distributed under the terms of the Creative Commons Attribution 4.0 International License (http://creativecommons.org/licenses/by/4.0/), which permits unrestricted use, distribution, and reproduction in any medium, provided you give appropriate credit to the original author(s) and the source, provide a link to the Creative Commons license, and indicate if changes were made. 
The results of Ran and Reurings were extended by Nieto and Rodríguez-López $[4,5]$ to the functions which are not necessarily continuous. As an application of their results, the authors also obtained a theorem on the existence of a unique solution for periodic boundary problems relative to ordinary differential equations.

Apart from the above, some very important work worth mentioning in this arena may be found in [6-14].

Some important works on fixed point theorems for set valued and multivalued contraction mappings were done by Nadler [15] and Assad and Kirk [16]. The concepts of fixed point theory and graph theory were combined by Espinola and Kirk [17] to prove some interesting fixed point theorems in $R$-trees. In 2008, Jachymski [18] came up with the interesting idea of using the language of graph theory in the study of fixed point results. $\mathrm{He}$ wanted to establish results that would eventually generalize the above mentioned results and also present some applications to the theory of linear operators. So, he studied the class of generalized Banach contractions on a metric space with a directed graph. The advantage of using graph theoretical concepts was that it helped him to describe the results in a unified way and also to weaken some conditions significantly. Some important work in this direction was carried out by Bojor [19, 20].

Very recently, some wonderful research on fixed point theory in a metric space endowed with a graph has been carried out by Alfuraidan [21, 22] and Alfuraidan and Khamsi [23].

Again, the study of coupled and common fixed point theorems remain a well motivated area of research in fixed point theory due to their applications in a wide variety of problems. For example, applications of coupled fixed points for binary mappings were studied by Bhaskar and Lakshmikantham [24]. They have used such fixed point results to prove the existence and uniqueness of solution for a periodic boundary value problem. Recently, Chifu and Petrusel [1] have developed some coupled fixed point results in metric space endowed with a directed graph to prove the existence of a continuous solution for a system of Fredholm and Volterra integral equations.

Following the same line, in the current paper, our aim is to extend some coupled coincidence and coupled common fixed point theorems for nonlinear contractions in partially ordered complete metric spaces endowed with a directed graph. Our results would bring about a more unified approach to the presentation of coupled coincidence and coupled common fixed point theorems. Also, as an application of our results, we aim to prove a theorem which can be used to test the existence of a solution for some particular integral equations.

Let $(X, d)$ be a metric space and $\Delta$ be the diagonal of the Cartesian product $X \times X$. Consider a directed graph $G$ such that the set $V(G)$ coincides with $X$ and $\Delta \subseteq E(G)$, where $E(G)$ is the set of edges of the graph $G$. Assume that $G$ has no parallel edges and so $G$ can be identified with the pair $(V(G), E(G))$. Also, denote by $G^{-1}$ the graph obtained from $G$ by reversing the direction of the edges in $G$. Thus,

$$
E\left(G^{-1}\right)=\{(x, y) \in X \times X:(y, x) \in E(G)\} .
$$

Definition 1.1 (cf. [11]) An element $(x, y) \in X \times X$ is called a coupled coincidence point of the functions $F: X \times X \rightarrow X$ and $g: X \rightarrow X$ if

$$
F(x, y)=g x \quad \text { and } \quad F(y, x)=g y .
$$


Let us denote the set of all coupled coincidence points of $F$ and $g$ as CCoin $(F g)$.

Definition $1.2(c f$. [11]) An element $(x, y) \in X \times X$ is called a coupled common fixed point of the functions $F: X \times X \rightarrow X$ and $g: X \rightarrow X$ if

$$
F(x, y)=g(x)=x \quad \text { and } \quad F(y, x)=g(y)=y .
$$

Definition 1.3 ( $c f$. [11]) Let $X$ be a nonempty set. Then the functions $F: X \times X \rightarrow X$ and $g: X \rightarrow X$ are said to be commutative if

$$
g(F(x, y))=F(g x, g y), \quad \forall x, y \in X
$$

Definition 1.4 (cf. [18]) A function $g: X \rightarrow X$ is G-continuous if

(i) for all $x, x^{*} \in X$ and any sequence $\left(n_{i}\right)_{i \in N}$ of positive integers, $\left(x_{n_{i}}\right) \rightarrow x^{*}$ and $\left(x_{n_{i}}, x_{n_{i+1}}\right) \in E(G)$, for $n \in N$, implies $g\left(x_{n_{i}}\right) \rightarrow g x^{*}$;

(ii) for all $y, y^{*} \in X$ and any sequence $\left(n_{i}\right)_{i \in N}$ of positive integers, $\left(y_{n_{i}}\right) \rightarrow y^{*}$ and $\left(y_{n_{i}}, y_{n_{i+1}}\right) \in E\left(G^{-1}\right)$, for $n \in N$, implies $g\left(y_{n_{i}}\right) \rightarrow g y^{*}$.

Definition 1.5 (cf. [1]) A function $F: X \times X \rightarrow X$ is G-continuous if for all $(x, y),\left(x^{*}, y^{*}\right) \in$ $X \times X$ and any sequence $\left\{n_{i}\right\}_{i \in N}$ of positive integers, $\left\{x_{n_{i}}\right\} \rightarrow x^{*},\left\{y_{n_{i}}\right\} \rightarrow y^{*}$, as $i \rightarrow \infty$ and $\left(x_{n_{i}}, x_{n_{i+1}}\right) \in E(G),\left(y_{n_{i}}, y_{n_{i+1}}\right) \in E\left(G^{-1}\right)$, for $n \in N$, implies $F\left(x_{n_{i}}, y_{n_{i}}\right) \rightarrow F\left(x^{*}, y^{*}\right)$ and $F\left(y_{n_{i}}, x_{n_{i}}\right) \rightarrow F\left(y^{*}, x^{*}\right)$.

Definition $1.6(c f$. [1]) Let $(X, d)$ be a complete metric space endowed with a directed graph $G$. Then the triple $(X, d, G)$ has the property $(A)$ if

(i) for any sequence $\left\{x_{n}\right\}_{n \in N}$ in $X$ such that $\left\{x_{n}\right\} \rightarrow x^{*}$ and $\left(x_{n}, x_{n+1}\right) \in E(G)$, $\left(x_{n}, x^{*}\right) \in E(G)$

(ii) for any sequence $\left\{y_{n}\right\}_{n \in N}$ in $X$ such that $\left\{y_{n}\right\} \rightarrow y^{*}$ and $\left(y_{n}, y_{n+1}\right) \in E\left(G^{-1}\right)$, $\left(y_{n}, y^{*}\right) \in E\left(G^{-1}\right)$.

\section{Main results}

Now we are ready to discuss our main results. With the help of preliminaries and some definitions given below, first we establish some lemmas which will be useful later.

Suppose that $(X, d)$ be a metric space endowed with a directed graph $G$. Let us consider the mappings $F: X \times X \rightarrow X$ and $g: X \rightarrow X$.

Define the set $(X \times X)_{F g}$ as

$$
(X \times X)_{F g}=\left\{(x, y) \in X \times X:(g x, F(x, y)) \in E(G) \text { and }(g y, F(y, x)) \in E\left(G^{-1}\right)\right\} .
$$

Definition 2.1 The mapping $F: X \times X \rightarrow X$ is called a $G$ - $g$-contraction if

(i) $g$ is edge preserving, i.e., $(g x, g u) \in E(G)$ and $(g y, g v) \in E\left(G^{-1}\right) \Longrightarrow(g(g x), g(g u)) \in E(G)$ and $(g(g y), g(g v)) \in E\left(G^{-1}\right)$;

(ii) $F$ is $g$-edge preserving, i.e., $(g x, g u) \in E(G)$ and $(g y, g v) \in E\left(G^{-1}\right) \Longrightarrow(F(x, y), F(u, v)) \in E(G)$ and $(F(y, x), F(v, u)) \in E\left(G^{-1}\right) ;$

(iii) for all $x, y, u, v \in X$ such that $(g x, g u) \in E(G)$ and $(g y, g v) \in E\left(G^{-1}\right)$, $d(F(x, y), F(u, v)) \leq \frac{k}{2}[d(g x, g u)+d(g y, g v)]$, where $k \in[0,1 / 2)$ is called the contraction constant of $F$. 
Lemma 2.2 Suppose that $F: X \times X \rightarrow X$ is g-edge preserving and $F(X \times X) \subseteq g(X)$. Also let $\left\{x_{n}\right\},\left\{y_{n}\right\},\left\{u_{n}\right\},\left\{v_{n}\right\}$ be sequences in the metric space $(X, d)$ endowed with a directed graph $G$. Then the following statements are true:

(i) $(g x, g u) \in E(G)$ and $(g y, g v) \in E\left(G^{-1}\right) \Longrightarrow\left(F\left(x_{n}, y_{n}\right), F\left(u_{n}, v_{n}\right)\right) \in E(G)$ and $\left(F\left(y_{n}, x_{n}\right), F\left(v_{n}, u_{n}\right)\right) \in E\left(G^{-1}\right), \forall n \in N$

(ii) $(x, y) \in(X \times X)_{F g} \Longrightarrow\left(F\left(x_{n}, y_{n}\right), F\left(x_{n+1}, y_{n+1}\right)\right) \in E(G)$ and $\left(F\left(y_{n}, x_{n}\right), F\left(y_{n+1}, x_{n+1}\right)\right) \in E\left(G^{-1}\right), \forall n \in N$;

(iii) $(x, y) \in(X \times X)_{F g} \Longrightarrow\left(F\left(x_{n}, y_{n}\right), F\left(y_{n}, x_{n}\right)\right) \in(X \times X)_{F g}, \forall n \in N$.

Proof We have $F(X \times X) \subseteq g(X)$,

$$
\begin{aligned}
& \text { set } F\left(x_{i}, y_{i}\right)=g\left(x_{i+1}\right) \text { and } F\left(y_{i}, x_{i}\right)=g\left(y_{i+1}\right), \\
& x=x_{0} \quad \text { and } y=y_{0} .
\end{aligned}
$$

(i) Let

$$
(g x, g u) \in E(G) \quad \text { and } \quad(g y, g v) \in E\left(G^{-1}\right) .
$$

Then, by the $g$-edge preserving property of $F$,

$$
\begin{aligned}
& (F(x, y), F(u, v)) \in E(G) \quad \text { and } \quad(F(y, x), F(v, u)) \in E\left(G^{-1}\right) \\
& \left.\Longrightarrow \quad\left(g x_{1}, g u_{1}\right) \in E(G) \quad \text { and } \quad\left(g y_{1}, g v_{1}\right) \in E\left(G^{-1}\right) \quad \text { by }(2.1)\right) .
\end{aligned}
$$

Again, applying the $g$-edge preserving property of $F$,

$$
\left(F\left(x_{1}, y_{1}\right), F\left(u_{1}, v_{1}\right)\right) \in E(G) \quad \text { and } \quad\left(F\left(y_{1}, x_{1}\right), F\left(v_{1}, u_{1}\right)\right) \in E\left(G^{-1}\right) .
$$

Hence, using (2.1), (2.2) and $g$-edge preserving property of $F$ repeatedly,

$$
\left(F\left(x_{n}, y_{n}\right), F\left(u_{n}, v_{n}\right)\right) \in E(G) \quad \text { and } \quad\left(F\left(y_{n}, x_{n}\right), F\left(v_{n}, u_{n}\right)\right) \in E\left(G^{-1}\right), \quad \forall n \in N
$$

(ii)

$$
\begin{aligned}
& (x, y) \in(X \times X)_{F g} \\
& \Longrightarrow \quad\left(x_{0}, y_{0}\right) \in(X \times X)_{F g} \quad(\text { by }(2.2)) \\
& \Longrightarrow \quad\left(g x_{0}, F\left(x_{0}, y_{0}\right)\right) \in E(G) \quad \text { and } \quad\left(g y_{0}, F\left(y_{0}, x_{0}\right)\right) \in E\left(G^{-1}\right) \\
& \Longrightarrow \quad\left(g x_{0}, g x_{1}\right) \in E(G) \quad \text { and } \quad\left(g y_{0}, g y_{1}\right) \in E\left(G^{-1}\right) \quad(\text { by }(2.1))
\end{aligned}
$$

Then, by the $g$-edge preserving property of $F$,

$$
\left(F\left(x_{0}, y_{0}\right), F\left(x_{1}, y_{1}\right)\right) \in E(G) \quad \text { and } \quad\left(F\left(y_{0}, x_{0}\right), F\left(y_{1}, x_{1}\right)\right) \in E\left(G^{-1}\right) .
$$

Thus, using (2.1) and $g$-edge preserving property of $F$ repeatedly,

$$
\left(F\left(x_{n}, y_{n}\right), F\left(x_{n+1}, y_{n+1}\right)\right) \in E(G) \quad \text { and } \quad\left(F\left(y_{n}, x_{n}\right), F\left(y_{n+1}, x_{n+1}\right)\right) \in E\left(G^{-1}\right), \quad \forall n \in N
$$


(iii)

$$
\begin{aligned}
& (x, y) \in(X \times X)_{F g} \\
& \Rightarrow \quad\left(F\left(x_{n}, y_{n}\right), F\left(x_{n+1}, y_{n+1}\right)\right) \in E(G) \text { and }\left(F\left(y_{n}, x_{n}\right), F\left(y_{n+1}, x_{n+1}\right)\right) \in E\left(G^{-1}\right) \\
& \Longrightarrow\left(g x_{n+1}, F\left(x_{n+1}, y_{n+1}\right)\right) \in E(G) \text { and }\left(g y_{n+1}, F\left(y_{n+1}, x_{n+1}\right)\right) \in E\left(G^{-1}\right) \quad(\text { by }(2.1)) \\
& \Longrightarrow \quad\left(x_{n+1}, y_{n+1}\right) \in(X \times X)_{F g} .
\end{aligned}
$$

Lemma 2.3 Let $(X, d)$ be a metric space endowed with a directed graph $G$. Let $F: X \times X \rightarrow$ $X$ be a G-g-contraction with contraction constant $k \in[0,1 / 2)$ and $F(X \times X) \subseteq g(X)$. Also suppose that $\left\{x_{n}\right\},\left\{y_{n}\right\}$ be sequences in $X$. Then, for $(x, y) \in(X \times X)_{F g}$, there exist $r(x, y) \geq 0$ and $k \in[0,1 / 2)$ such that

$$
d\left(g x_{n}, g x_{n+1}\right) \leq \frac{k^{n-1}}{2} r(x, y) \quad \text { and } \quad d\left(g y_{n}, g y_{n+1}\right) \leq \frac{k^{n-1}}{2} r(x, y) .
$$

Proof

$$
\begin{aligned}
& (x, y) \in(X \times X)_{F g} \\
& \Rightarrow \quad(g x, F(x, y)) \in E(G) \quad \text { and } \quad(g y, F(y, x)) \in E\left(G^{-1}\right) \\
& \Rightarrow \quad\left(g x_{0}, g x_{1}\right) \in E(G) \quad \text { and } \quad\left(g y_{0}, g y_{1}\right) \in E\left(G^{-1}\right) .
\end{aligned}
$$

Then, by Lemma 2.2,

$$
\begin{aligned}
& \left(F\left(x_{n}, y_{n}\right), F\left(x_{n+1}, y_{n+1}\right)\right) \in E(G) \quad \text { and } \quad\left(F\left(y_{n}, x_{n}\right), F\left(y_{n+1}, x_{n+1}\right)\right) \in E\left(G^{-1}\right), \quad \forall n \in N \\
& \Longrightarrow \quad\left(g x_{n}, g x_{n+1}\right) \in E(G) \quad \text { and } \quad\left(g y_{n}, g y_{n+1}\right) \in E\left(G^{-1}\right), \quad \forall n \in N
\end{aligned}
$$

But $F$ is a $G$ - $g$-contraction, so

$$
\begin{aligned}
d\left(g x_{n}, g x_{n+1}\right)= & d\left(F\left(x_{n-1}, y_{n-1}\right), F\left(x_{n}, y_{n}\right)\right) \\
\leq & \frac{k}{2}\left[d\left(g x_{n-1}, g x_{n}\right)+d\left(g y_{n-1}, g y_{n}\right)\right] \\
= & \frac{k}{2}\left[d\left(F\left(x_{n-2}, y_{n-2}\right), F\left(x_{n-1}, y_{n-1}\right)\right)+d\left(F\left(y_{n-2}, x_{n-2}\right), F\left(y_{n-1}, x_{n-1}\right)\right)\right] \\
\leq & \frac{k^{2}}{2}\left[d\left(g x_{n-2}, g x_{n-1}\right)+d\left(g y_{n-2}, g y_{n-1}\right)\right] \\
& \cdots \\
\leq & \frac{k^{n-1}}{2}\left[d\left(g x_{0}, g x_{1}\right)+d\left(g y_{0}, g y_{1}\right)\right] .
\end{aligned}
$$

Then $d\left(g x_{n}, g x_{n+1}\right) \leq \frac{k^{n-1}}{2} r(x, y)$, where $r(x, y):=d\left(g x_{0}, g x_{1}\right)+d\left(g y_{0}, g y_{1}\right)$.

Similarly, $d\left(g y_{n}, g y_{n+1}\right) \leq \frac{k^{n-1}}{2} r(x, y)$.

Lemma 2.4 Suppose that $(X, d)$ is a complete metric space endowed with a directed graph $G$. Let $F: X \times X \rightarrow X$ be a G-g-contraction with contraction constant $k \in[0,1 / 2)$ and $F(X \times X) \subseteq g(X)$. Also let $\left\{x_{n}\right\},\left\{y_{n}\right\}$ be sequences in $X$. Then, for each $(x, y) \in(X \times X)_{F g}$, there exist $x^{*}, y^{*} \in X$ such that $g x_{n} \rightarrow x^{*}$ and $g y_{n} \rightarrow y^{*}$, as $n \rightarrow \infty$. 
Proof Let $(x, y) \in(X \times X)_{F g}$.

Then, using Lemma 2.3,

$$
\begin{aligned}
& d\left(g x_{n}, g x_{n+1}\right) \leq \frac{k^{n-1}}{2} r(x, y), \quad \text { where } k \in[0,1 / 2), \\
& d\left(g y_{n}, g y_{n+1}\right) \leq \frac{k^{n-1}}{2} r(x, y), \quad \text { for all } n \in N
\end{aligned}
$$

Let $m>n$. We have

$$
\begin{aligned}
& d\left(g x_{n}, g x_{m}\right) \leq d\left(g x_{n}, g x_{n+1}\right)+d\left(g x_{n+1}, g x_{n+2}\right)+\cdots+d\left(g x_{m-1}, g x_{m}\right) \\
& \leq \frac{k^{n-1}}{2} r(x, y)+\frac{k^{n}}{2} r(x, y)+\cdots+\frac{k^{m-2}}{2} r(x, y) \\
&=\frac{k^{n-1}}{2} r(x, y)\left(1+k+\cdots+k^{m-n-1}\right) \\
&=\frac{k^{n-1}}{2} r(x, y)\left(\frac{1-k^{m-n}}{1-k}\right) \\
& \Longrightarrow \quad d\left(g x_{n}, g x_{m}\right) \rightarrow 0, \quad \text { for large } m, n .
\end{aligned}
$$

Hence, $\left(g x_{n}\right)_{n \in N}$ is a Cauchy sequence.

Similarly, $\left(g y_{n}\right)_{n \in N}$ is also a Cauchy sequence.

Also, $(X, d)$ is complete. So, there exist, say, $x^{*}, y^{*} \in X$ such that

$$
\lim _{n \rightarrow \infty} g x_{n}=x^{*} \text { and } \lim _{n \rightarrow \infty} g y_{n}=y^{*}
$$

Now we discuss our main results.

Theorem 2.5 Suppose that $(X, d)$ is a complete metric space endowed with a directed graph G. Let $F: X \times X \rightarrow X$ be a G-g-contraction with contraction constant $k \in[0,1 / 2)$ and $F(X \times X) \subseteq g(X)$. Let $g$ be G-continuous and commutes with $F$. Also, we assume either

(i) $F$ is G-continuous, or

(ii) the triple $(X, d, G)$ has the property $(A)$.

Then $\operatorname{CCoin}(F g) \neq \phi$ iff $(X \times X)_{F g} \neq \phi$.

Proof Suppose that CCoin $(F g) \neq \phi$.

Then there exists some $\left(x^{*}, y^{*}\right) \in \operatorname{CCoin}(F g)$, i.e., $g x^{*}=F\left(x^{*}, y^{*}\right)$ and $g y^{*}=F\left(y^{*}, x^{*}\right)$.

So,

$$
\begin{aligned}
& \left(g x^{*}, F\left(x^{*}, y^{*}\right)\right)=\left(g x^{*}, g x^{*}\right) \in \Delta \subseteq E(G) \text { and } \\
& \left(g y^{*}, F\left(y^{*}, x^{*}\right)\right)=\left(g y^{*}, g y^{*}\right) \in \Delta \subseteq E\left(G^{-1}\right) \\
& \Longrightarrow \quad\left(x^{*}, y^{*}\right) \in(X \times X)_{F g} \\
& \Longrightarrow \quad(X \times X)_{F g} \neq \phi .
\end{aligned}
$$

Next, let us assume that $(X \times X)_{F g} \neq \phi$. 
Then there exists $\left(x_{0}, y_{0}\right) \in(X \times X)_{F g}$, i.e., $\left(g x_{0}, F\left(x_{0}, y_{0}\right)\right) \in E(G)$ and $\left(g y_{0}, F\left(y_{0}, x_{0}\right)\right) \in$ $E\left(G^{-1}\right)$.

Then, by Lemma 2.2(ii), we have a sequence $\left(n_{i}\right)_{i \in N}$ of positive integers such that

$$
\left(F\left(x_{n_{i}}, y_{n_{i}}\right), F\left(x_{n_{i}+1}, y_{n_{i}+1}\right)\right) \in E(G) \quad \text { and } \quad\left(F\left(y_{n_{i}}, x_{n_{i}}\right), F\left(y_{n_{i}+1}, x_{n_{i}+1}\right)\right) \in E\left(G^{-1}\right)
$$

Using (2.1) and (2.2),

$$
\left(g x_{n_{i}+1}, g x_{n_{i}+2}\right) \in E(G) \quad \text { and } \quad\left(g y_{n_{i}+1}, g y_{n_{i}+2}\right) \in E\left(G^{-1}\right) .
$$

Also, from Lemma 2.4,

$$
\lim _{n \rightarrow \infty} g x_{n_{i}}=x^{*} \text { and } \lim _{n \rightarrow \infty} g y_{n_{i}}=y^{*}
$$

But $g$ is G-continuous

$$
\Longrightarrow \quad \lim _{n \rightarrow \infty} g\left(g x_{n_{i}}\right)=g x^{*} \text { and } \lim _{n \rightarrow \infty} g\left(g y_{n_{i}}\right)=g y^{*}
$$

Also, since $F$ and $g$ are commutative,

$$
\begin{aligned}
& g\left(g x_{n_{i+1}}\right)=g\left(F\left(x_{n_{i}}, y_{n_{i}}\right)\right) \quad \text { and } g\left(g y_{n_{i+1}}\right)=g\left(F\left(y_{n_{i}}, x_{n_{i}}\right)\right) \\
& \Longrightarrow \quad g\left(g x_{n_{i+1}}\right)=F\left(g x_{n_{i}}, g y_{n_{i}}\right) \quad \text { and } g\left(g y_{n_{i+1}}\right)=F\left(g y_{n_{i}}, g x_{n_{i}}\right)
\end{aligned}
$$

Finally, we show that

$$
g x^{*}=F\left(x^{*}, y^{*}\right) \text { and } g y^{*}=F\left(y^{*}, x^{*}\right) .
$$

Let $F$ be $G$-continuous.

Then, from (2.6), we have

$$
\begin{gathered}
\lim _{n \rightarrow \infty} g\left(g x_{n_{i}+1}\right)=\lim _{n \rightarrow \infty} F\left(g x_{n_{i}}, g y_{n_{i}}\right) \\
\Longrightarrow \quad g x^{*}=F\left(x^{*}, y^{*}\right) \quad \text { and } \\
\lim _{n \rightarrow \infty} g\left(g y_{n_{i}+1}\right)=\lim _{n \rightarrow \infty} F\left(g y_{n_{i}}, g x_{n_{i}}\right) \\
\Longrightarrow g y^{*}=F\left(y^{*}, x^{*}\right) .
\end{gathered}
$$

Thus, $\left(x^{*}, y^{*}\right)$ is a coupled coincidence point of the mapping $F$ and $g$, i.e., $\operatorname{CCoin}(F g) \neq \phi$. Next, we assume that property $(A)$ holds.

From (2.3) and (2.4), we have

$$
\begin{aligned}
& g x_{n_{i}} \rightarrow x^{*}, \quad \text { as } i \rightarrow \infty \quad \text { and } \quad\left(g x_{n_{i}}, g x_{n_{i}+1}\right) \in E(G) \quad \text { and } \\
& g y_{n_{i}} \rightarrow y^{*}, \quad \text { as } i \rightarrow \infty \quad \text { and } \quad\left(g y_{n_{i}}, g y_{n_{i}+1}\right) \in E\left(G^{-1}\right) .
\end{aligned}
$$

Therefore, using property $(A)$,

$$
\left(g x_{n_{i}}, x^{*}\right) \in E(G) \text { and }\left(g y_{n_{i}}, y^{*}\right) \in E\left(G^{-1}\right)
$$


So,

$$
\begin{aligned}
d\left(g x^{*}, F\left(x^{*}, y^{*}\right)\right) & \leq d\left(g x^{*}, g\left(g x_{n_{i}+1}\right)\right)+d\left(g\left(g x_{n_{i}+1}\right), F\left(x^{*}, y^{*}\right)\right) \\
& =d\left(g x^{*}, g\left(g x_{n_{i}+1}\right)\right)+d\left(F\left(g x_{n_{i}}, g y_{n_{i}}\right), F\left(x^{*}, y^{*}\right)\right) \\
& \leq d\left(g x^{*}, g\left(g x_{n_{i}+1}\right)\right)+\frac{k}{2}\left[d\left(g\left(g x_{n_{i}}\right), g x^{*}\right)+d\left(g\left(g y_{n_{i}}\right), g y^{*}\right)\right] .
\end{aligned}
$$

Now, taking the limit as $n \rightarrow \infty$,

$$
d\left(g x^{*}, F\left(x^{*}, y^{*}\right)\right)=0 \quad \Longrightarrow \quad g x^{*}=F\left(x^{*}, y^{*}\right) .
$$

In a similar way we can obtain $g y^{*}=F\left(y^{*}, x^{*}\right)$.

Theorem 2.6 Suppose that the hypotheses of Theorem 2.5 hold. Besides, let for every $(x, y),\left(x^{*}, y^{*}\right) \in X \times X$ there exist $(u, v) \in X \times X$ such that

$$
\begin{array}{lc}
(F(x, y), F(u, v)) \in E(G), \quad & (F(y, x), F(v, u)) \in E\left(G^{-1}\right) \quad \text { and } \\
\left(F\left(x^{*}, y^{*}\right), F(u, v)\right) \in E(G), & \left(F\left(y^{*}, x^{*}\right), F(v, u)\right) \in E\left(G^{-1}\right) .
\end{array}
$$

Then $F$ and $g$ have a unique coupled common fixed point.

Proof Let $(x, y)$ and $\left(x^{*}, y^{*}\right)$ be coupled coincidence points, i.e.,

$$
\begin{aligned}
& g x=F(x, y), \quad g y=F(y, x) \quad \text { and } \\
& g x^{*}=F\left(x^{*}, y^{*}\right), \quad g y^{*}=F\left(y^{*}, x^{*}\right) .
\end{aligned}
$$

By hypothesis, we have

$$
\begin{aligned}
& (F(x, y), F(u, v)) \in E(G) \quad \text { and } \quad(F(y, x), F(v, u)) \in E\left(G^{-1}\right), \\
& \left(F\left(x^{*}, y^{*}\right), F(u, v)\right) \in E(G) \quad \text { and } \quad\left(F\left(y^{*}, x^{*}\right), F(v, u)\right) \in E\left(G^{-1}\right) .
\end{aligned}
$$

Set $F\left(u_{n}, v_{n}\right)=g u_{n+1}, u=u_{0}$, and $F\left(v_{n}, u_{n}\right)=g v_{n+1}, v=v_{0}$.

Then, using (2.7) and (2.8); (2.9) and (2.10) can be written as

$$
\begin{aligned}
& \left(g x, g u_{1}\right) \in E(G), \quad\left(g y, g v_{1}\right) \in E\left(G^{-1}\right) \quad \text { and } \\
& \left(g x^{*}, g u_{1}\right) \in E(G), \quad\left(g y^{*}, g v_{1}\right) \in E\left(G^{-1}\right) .
\end{aligned}
$$

But $F$ is $g$-edge preserving, so

$$
\begin{array}{cc}
\left(F(x, y), F\left(u_{1}, v_{1}\right)\right) \in E(G), & \left(F(y, x), F\left(v_{1}, u_{1}\right)\right) \in E\left(G^{-1}\right) \quad \text { and } \\
\left(F\left(x^{*}, y^{*}\right), F\left(u_{1}, v_{1}\right)\right) \in E(G), & \left(F\left(y^{*}, x^{*}\right), F\left(v_{1}, u_{1}\right)\right) \in E\left(G^{-1}\right) \\
\Longrightarrow \quad\left(g x, g u_{2}\right) \in E(G), & \left(g y, g v_{2}\right) \in E\left(G^{-1}\right) \text { and } \\
\left(g x^{*}, g u_{2}\right) \in E(G), & \left(g y^{*}, g v_{2}\right) \in E\left(G^{-1}\right) .
\end{array}
$$


Using the $g$-edge preserving property of $F$ repeatedly, $\forall n \geq 1$, we obtain

$$
\begin{aligned}
& \left(g x, g u_{n}\right) \in E(G), \quad\left(g y, g v_{n}\right) \in E\left(G^{-1}\right) \quad \text { and } \\
& \left(g x^{*}, g u_{n}\right) \in E(G), \quad\left(g y^{*}, g v_{n}\right) \in E\left(G^{-1}\right) .
\end{aligned}
$$

Therefore,

$$
\begin{aligned}
& d\left(g x, g x^{*}\right) \leq d\left(g x, g u_{n+1}\right)+d\left(g u_{n+1}, g x^{*}\right) \\
& =d\left(F(x, y), F\left(u_{n}, v_{n}\right)\right)+d\left(F\left(u_{n}, v_{n}\right), F\left(x^{*}, y^{*}\right)\right) \\
& \leq \frac{k}{2}\left[d\left(g x, g u_{n}\right)+d\left(g y, g v_{n}\right)+d\left(g u_{n}, g x^{*}\right)+d\left(g v_{n}, g y^{*}\right)\right] \\
& =\frac{k}{2}\left[d\left(F(x, y), F\left(u_{n-1}, v_{n-1}\right)\right)+d\left(F(y, x), F\left(v_{n-1}, u_{n-1}\right)\right)\right. \\
& \left.+d\left(F\left(u_{n-1}, v_{n-1}\right), F\left(x^{*}, y^{*}\right)\right)+d\left(F\left(v_{n-1}, u_{n-1}\right), F\left(y^{*}, x^{*}\right)\right)\right] \\
& \leq \frac{k^{2}}{2}\left[d\left(g x, g u_{n-1}\right)+d\left(g y, g v_{n-1}\right)+d\left(g u_{n-1}, g x^{*}\right)+d\left(g v_{n-1}, g y^{*}\right)\right] \\
& \text {.. } \\
& \text {... } \\
& \leq \frac{k^{n}}{2}\left[d\left(g x, g u_{0}\right)+d\left(g y, g v_{0}\right)+d\left(g u_{0}, g x^{*}\right)+d\left(g v_{0}, g y^{*}\right)\right] \\
& \Longrightarrow \quad d\left(g x, g x^{*}\right)=0, \quad \text { as } n \rightarrow \infty \\
& \Longrightarrow g x=g x^{*} \text {. }
\end{aligned}
$$

Similarly,

$$
g y=g y^{*}
$$

Let $g x=g x^{*}=m$ and $g y=g y^{*}=n$.

Then, using commutativity of $F$ and $g$, (2.7) gives

$$
\begin{gathered}
g(g x)=g(F(x, y))=F(g x, g y) \quad \text { and } \quad g(g y)=g(F(y, x))=F(g y, g x) \\
\Longrightarrow \quad g m=F(m, n) \quad \text { and } \quad g n=F(n, m) .
\end{gathered}
$$

Thus, $(m, n)$ is a coupled coincidence point.

So, repeating the earlier argument for $(x, y)$ and $(m, n)$,

$$
\begin{aligned}
g x & =g m \quad \text { and } \quad g y=g n \\
& \Longrightarrow m=g m \quad \text { and } n=g n .
\end{aligned}
$$

Thus,

$$
m=g m=F(m, n) \quad \text { and } \quad n=g n=F(n, m) .
$$

So, $(m, n)$ is a coupled common fixed point of $F$ and $g$. 
Finally, we prove that the coupled common fixed point of $F$ and $g$ is unique. Let us suppose that $(p, q)$ is another coupled common fixed point of $F$ and $g$. Then

$$
p=g p=F(p, q) \quad \text { and } \quad q=g q=F(q, p) .
$$

But, from (2.11) and (2.12),

$$
g p=g m=m \quad \text { and } \quad g q=g n=n .
$$

So, from (2.13) and (2.14),

$$
p=m \text { and } q=n \text {. }
$$

Hence the coupled common fixed point of $F$ and $g$ is unique.

Remark 2.7 As noted from Lemma 2.2, Lemma 2.3, and Lemma 2.4, we have proved our results under strong conditions, like $F$ being $g$-invariant, i.e., $F(X \times X) \subseteq g(X)$, and we restricted the contraction constant $k$ in $[0,1 / 2)$. It would be a good subject to investigate whether the results can be extended to the case when $k \in[0,1)$ and whether the invariant condition can be weakened, as the authors are unsure of these facts at present.

\section{Application}

In this section, to discuss the application of our main results we establish an existence theorem in a metric space with graph for the solution of the integral equations.

Let us consider the following integral equations:

$$
\left.\begin{array}{ll}
x(t)=\int_{0}^{T} f(t, x(s), y(s)) d s, & t \in[0, T], \\
y(t)=\int_{0}^{T} f(t, y(s), x(s)) d s, & t \in[0, T],
\end{array}\right\}
$$

where $T$ is a positive real number and $f:[0, T] \times \mathbb{R} \times \mathbb{R} \rightarrow \mathbb{R}$.

Let us consider $X=C([0, T], \mathbb{R})$ with the metric $d: X \times X \rightarrow \mathbb{R}$ defined by

$$
d(x, y)=\sup _{t \in[0, T]}|x(t)-y(t)|, \quad \forall x, y \in X .
$$

Further, define a graph $\mathrm{G}$ using a partial order relation, i.e., $x, y \in X, x \leq y \Longleftrightarrow x(t) \leq y(t)$, for any $t \in[0, T]$.

So, we have

$$
\begin{aligned}
& E(G):=\{(x, y) \in X \times X: x \leq y\}, \\
& E\left(G^{-1}\right):=\{(x, y) \in X \times X: y \leq x\} .
\end{aligned}
$$

Also, $\Delta(X \times X) \subseteq E(G)$ and $(X, d, G)$ has property $(A)$.

It is a routine verification to check that $(X, d)$ is a complete metric space with a directed graph $G$. 
Theorem 3.1 Suppose, for the integral equations (3.1),

(i) $f:[0, T] \times \mathbb{R} \times \mathbb{R} \rightarrow \mathbb{R}$ is continuous;

(ii) for all $t \in[0, T]$ and $x, y, u, v \in \mathbb{R}$ with $x \leq u, v \leq y, f(t, x, y) \leq f(t, u, v)$;

(iii) for each $t \in[0, T]$ and $x, y, u, v \in \mathbb{R}$ with $x \leq u, v \leq y$, there exists $k \in[0,1)$ such that $|f(t, x, y)-f(t, u, v)| \leq \frac{k}{2 T}(|x-u|+|y-v|)$

(iv) there exists $\left(x_{0}, y_{0}\right) \in X \times X$ such that for all $t \in[0, T]$,

$$
x(t) \leq \int_{0}^{T} f\left(t, x_{0}(s), y_{0}(s)\right) d s \text { and } \int_{0}^{T} f\left(t, y_{0}(s), x_{0}(s)\right) d s \leq y(t) .
$$

Then there exists at least one solution of (3.1).

Proof Let $F: X \times X \rightarrow X$ and $g: X \rightarrow X$ be defined as

$$
\begin{aligned}
& F(x, y)(t)=\int_{0}^{T} f(t, x(s), y(s)) d s, \quad t \in[0, T] \text { and } \\
& g(x)(t)=x(t) .
\end{aligned}
$$

Then (3.1) is equivalent to

$$
\begin{aligned}
& g(x)=F(x, y), \\
& g(y)=F(y, x),
\end{aligned}
$$

i.e., the solution of (3.1) is a coupled coincidence point of the mappings $F$ and $g$, provided we verify the conditions in Theorem 2.5 .

To verify this, we use that $g$ is edge preserving.

Suppose that $x, y, u, v \in X$ such that $g(x) \leq g(u)$ and $g(v) \leq g(y)$.

Then, for each $t \in[0, T]$,

$$
\begin{aligned}
& F(x, y)(t)=\int_{0}^{T} f(t, x(s), y(s)) d s \\
&=\int_{0}^{T} f(t, g(x)(s), g(y)(s)) d s \\
& \leq \int_{0}^{T} f(t, g(u)(s), g(v)(s)) d s \\
&=\int_{0}^{T} f(t, u(s), v(s)) d s \\
&=F(u, v)(t) \\
& \Longrightarrow \quad F(x, y)(t) \leq F(u, v)(t), \quad \text { for each } t \in[0, T] \\
& \Longrightarrow \quad(F(x, y), F(u, v)) \in E(G) .
\end{aligned}
$$

Similarly,

$$
F(v, u)(t) \leq F(y, x)(t), \quad \text { for each } t \in[0, T] \quad \Longrightarrow \quad(F(y, x), F(v, u)) \in E\left(G^{-1}\right) .
$$

Thus, $F$ is $g$-edge preserving. 
Next, we show that $F$ is a $G$ - $g$-contraction. We have

$$
\begin{aligned}
|F(x, y)(t)-F(u, v)(t)| & \leq \int_{0}^{T}|f(t, x(s), y(s))-f(t, u(s), v(s))| d s \\
& \leq \frac{k}{2 T} \int_{0}^{T}(|x(s)-u(s)|+|y(s)-v(s)|) d s \\
& \leq \frac{k}{2 T} \int_{0}^{T}\left(\sup _{z \in[0, T]}|x(z)-u(z)|+\sup _{z \in[0, T]}|y(z)-v(z)|\right) d s \\
& =\frac{k}{2}\left[\sup _{z \in[0, T]}|x(z)-u(z)|+\sup _{z \in[0, T]}|y(z)-v(z)|\right] .
\end{aligned}
$$

Therefore,

$$
\begin{aligned}
& \sup _{z \in[0, T]}|F(x, y)(t)-F(u, v)(t)| \\
& \quad \leq \frac{k}{2}\left[\sup _{z \in[0, T]}|g(x)(z)-g(u)(z)|+\sup _{z \in[0, T]}|g(y)(z)-g(v)(z)|\right] .
\end{aligned}
$$

This gives, $\forall x, y, u, v \in X$ with $g x \leq g u$ and $g v \leq g y$,

$$
d(F(x, y), F(u, v)) \leq \frac{k}{2}[d(g x, g u)+d(g y, g v)] .
$$

This implies that $F$ is a $G$-g-contraction.

Next, condition (iv) in the hypothesis implies that there exists $\left(x_{0}, y_{0}\right) \in X \times X$ such that

$$
\begin{aligned}
& x_{0}(t) \leq \int_{0}^{T} f\left(t, x_{0}(s), y_{0}(s)\right) d s \text { and } \\
& \int_{0}^{T} f\left(t, y_{0}(s), x_{0}(s)\right) d s \leq y_{0}(t) .
\end{aligned}
$$

But $x_{0}(t)=g\left(x_{0}\right)(t)$ and $y_{0}(t)=g\left(y_{0}\right)(t)$.

Therefore,

$$
\begin{aligned}
& g\left(x_{0}\right) \leq F\left(x_{0}, y_{0}\right) \quad \text { and } F\left(y_{0}, x_{0}\right) \leq g\left(y_{0}\right) \\
& \quad \Longrightarrow \quad\left(g\left(x_{0}\right), F\left(x_{0}, y_{0}\right)\right) \in E(G) \text { and }\left(g\left(y_{0}\right), F\left(y_{0}, x_{0}\right)\right) \in E\left(G^{-1}\right) \\
& \Longrightarrow(X \times X)_{F g} \neq \phi .
\end{aligned}
$$

Also, $F$ and $g$ are commutative and $F(X \times X) \subseteq g(X)$.

Further, condition (i) in the hypothesis implies that condition (i) of Theorem 2.5 is satisfied. Also, condition (ii) of Theorem 2.5 holds by the fact that $(X, d, G)$ has property $(A)$.

Thus, all conditions of Theorem 2.5 are fulfilled.

Hence, there exists a point $\left(x^{*}, y^{*}\right) \in X \times X$ such that

$$
\begin{aligned}
& g x^{*}=F\left(x^{*}, y^{*}\right) \quad \text { and } \\
& g y^{*}=F\left(y^{*}, x^{*}\right) .
\end{aligned}
$$


Hence, by the definition of $g$,

$$
\begin{aligned}
& x^{*}=g x^{*}=F\left(x^{*}, y^{*}\right) \quad \text { and } \\
& y^{*}=g y^{*}=F\left(y^{*}, x^{*}\right),
\end{aligned}
$$

i.e., $\left(x^{*}, y^{*}\right)$ is a solution of the system (3.1).

\section{Conclusion}

In this article, we have proved the existence of a coupled coincidence and unique coupled common fixed point for a contraction mapping in a partially ordered complete metric space endowed with a directed graph. Our results bring about a more unified approach to the presentation of coupled coincidence and coupled common fixed point theorems because of the use of graph theoretical concepts instead of a partial order.

Competing interests

The authors declare that they have no competing interests.

\section{Authors' contributions}

All authors contributed equally to the writing of this paper. All authors read and approved the final manuscript.

\section{Acknowledgements}

The authors express their heartfelt gratitude to the reviewers for their excellent comments and suggestions which have immensely improved the quality and presentation of the paper. The research of the first author is partially supported by Department of Science and Technology, Govt. of India (No. DST/INSPIRE FELLOWSHIP/2012/444). The author gratefully acknowledges the support.

\section{Received: 14 September 2015 Accepted: 9 March 2016 Published online: 18 March 2016}

\section{References}

1. Chifu, C, Petrusel, G: New results on coupled fixed point theory in metric spaces endowed with a directed graph. Fixed Point Theory Appl. 2014, 151 (2014)

2. Boyd, DW, Wong, JS: On nonlinear contractions. Proc. Am. Math. Soc. 20, 458-464 (1969)

3. Ran, ACM, Reurings, MCB: A fixed point theorem in partially ordered sets and some applications to matrix equations. Proc. Am. Math. Soc. 132(5), 1435-1443 (2004)

4. Nieto, JJ, Rodríguez-López, R: Contractive mapping theorems in partially ordered sets and applications to ordinary differential equations. Order 22(3), 223-239 (2005)

5. Nieto, JJ, Rodríquez-López, R: Existence and uniqueness of fixed point in partially ordered sets and applications to ordinary differential equations. Acta Math. Sin. Engl. Ser. 23(12), 2205-2212 (2007)

6. Agarwal, RP, O'Regan, D: Fixed point theory for generalized contractions on spaces with two metrics. J. Math. Anal. Appl. 248(2), 402-414 (2000)

7. Aleomraninejad, SMA, Rezapour, S, Shahzad, N: Some fixed point results on a metric space with a graph. Topol. Appl. $159,659-663(2012)$

8. Beg, I, Butt, AR, Radojević, S: The contraction principle for set valued mappings on a metric space with a graph. Comput. Math. Appl. 60, 1214-1219 (2010)

9. Debnath, P: Fixed points of contractive set valued mappings with set valued domains on a metric space with graph. TWMS J. Appl. Eng. Math. 4(2), 169-174 (2014)

10. Gwozdz-Lukawska, G, Jachymski, J: IFS on a metric space with a graph structure and extensions of the Kelisky-Rivlin theorem. J. Math. Anal. Appl. 356, 453-463 (2009)

11. Lakshmikantham, V, Ćirić, L: Coupled fixed point theorems for nonlinear contractions in partially ordered metric spaces. Nonlinear Anal., Theory Methods Appl. 70(12), 4341-4349 (2009)

12. Nieto, JJ, Pouso, RL, Rodríguez-López, R: Fixed point theorems in ordered abstract spaces. Proc. Am. Math. Soc. 135, 2505-2517 (2007)

13. Petruşel, A, Rus, IA: Fixed point theorems in ordered L-spaces. Proc. Am. Math. Soc. 134, 411-418 (2006)

14. Sintunavarat, W, Radenović, S, Golubović, Z, Kumam, P: Coupled fixed point theorems for $f$-invariant set. Appl. Math. Inf. Sci. 7(1), 247-255 (2013)

15. Nadler, SB: Multi-valued contraction mappings. Pac. J. Math. 30(2), 475-488 (1969)

16. Assad, NA, Kirk, WA: Fixed point theorems for set-valued mappings of contractive type. Pac. J. Math. 43(3), 553-561 (1972)

17. Espinola, R, Kirk, WA: Fixed point theorems in $\mathbb{R}$-trees with applications to graph theory. Topol. Appl. 153, 1046-1055 (2006)

18. Jachymski, J: The contraction principle for mappings on a metric space with a graph. Proc. Am. Math. Soc. 136(4), 1359-1373 (2008) 
19. Bojor, F: Fixed point theorems for Reich type contractions on metric spaces with a graph. Nonlinear Anal., Theory Methods Appl. 75(9), 3895-3901 (2012)

20. Bojor, F: Fixed points of Kannan mappings in metric spaces endowed with a graph. An. Ştiinţ. Univ. 'Ovidius' Constanţa 20(1), 31-40 (2012)

21. Alfuraidan, MR: The contraction principle for multivalued mappings on a modular metric space with a graph. Can. Math. Bull. 59, 3-12 (2016). doi:10.4153/CMB-2015-029-x

22. Alfuraidan, MR: Remarks on monotone multivalued mappings on a metric space with graph. J. Inequal. Appl. 2015, 202 (2015). doi:10.1186/s13660-015-0712-6

23. Alfuraidan, MR, Khamsi, MA: Fixed points of monotone nonexpansive mappings on a hyperbolic metric space with a graph. Fixed Point Theory Appl. 2014, 44 (2015). doi:10.1186/s13663-015-0294-5

24. Bhaskar, TG, Lakshmikantham, V: Fixed point theorems in partially ordered metric spaces and applications. Nonlinear Anal., Theory Methods Appl. 65(7), 1379-1393 (2006)

Submit your manuscript to a SpringerOpen ${ }^{\circ}$ journal and benefit from:

- Convenient online submission

- Rigorous peer review

- Immediate publication on acceptance

- Open access: articles freely available online

- High visibility within the field

- Retaining the copyright to your article

Submit your next manuscript at $\boldsymbol{~ s p r i n g e r o p e n . c o m ~}$ 